\title{
CRITICAL PITTING POTENTIAL AND STRESS CORROSION CRACKING OF ALUMINUM ALLOY IN CHLORIDE MEDIA
}

\author{
M. Elboujdaini and M.T. Shehata \\ Materials Technology Laboratory/CANMET, Natural Resources Canada \\ 568 Booth St., Ottawa, Canada K1A OG1 \\ E. Ghali \\ Laval University, Department of Mining and Metallurgy, \\ Quebec, Quebec Canada G1K 7P4
}

The high strength-to-weight ratio of aluminum and its alloys has long attracted the attention of the aerospace, military, cans industries. Efforts are now spent to improve further corrosion resistance, workability, weldability, stress corrosion cracking and corrosion fatigue of Al alloys components to be used alongside traditional steel components.

When a metallic surface is not protected, it will suffer uniform corrosion. However, when the material forms a passive film, the uniform corrosion is replaced by localized corrosion, which is more dangerous, which results from the breakdown of the passive film. Under loading the localized corrosion or pitting can lead to stress corrosion cracking (SCC) and corrosion fatigue (CF). Transition from pitting attack to SCC has been noted in the literature for aluminum and its alloy as they fall into this class material that are thus susceptible to the SCC and CF phenomena, however, the mechanism for this transition is not well understood.

In this study, the critical pitting potential of aluminium alloys has been carried out by steady state and transient polarization measurements in chloride solution containing sulphate ions. Stress corrosion cracking (SCC) of aluminium alloy (Al-Mg-Si 6061T6) in chloride solution has been examined as a function of stress, $\mathrm{pH}$ and anodic polarization. Complementary to the electrochemical studies and SCC, the scanning electron microscopy (SEM) and X-ray photoelectron spectroscopy (XPS) were used to investigate the structure and chemical state of the electrode surface.

The paper deals with the pitting phenomenon leading to SCC and CF in aluminum alloys. The results are presented for the pitting studies by the potentiodynamic techniques, where potential control was maintained for SCC and CF tests samples by potentiostatic methods. Surface analysis and sample morphology as examined by SEM are presented. Examples of SEM observations are shown in Figure 1 for pit formation and in Figure 2 for SCC associated with pits.

\section{References}

1. R.T. Foley, Corrosion 42 (1986) p. 277.

2. K. Nisancioglu, O. Lunder and H. Holtan, Corrosion 41 (1985) p.247.

3. M. Elboujdaîni, E. Ghali and A. Galibois, J. Appl. Electrochem., 18 (1988) p.257.

4. F.M. Al-Kharafi and W.A. Badawy, Corrosion, Vol. 54, No. 5 (1998) p. 377.

5. C.D. Wagner, W.M. Riggs, L.E. Davis, J.F. Moulder, "Handbook of X-ray Photoelectron Spectroscopy”, (edited by G.E. Muilenberg), Perkin-Elmer Corp. Minnesota, (1979). 

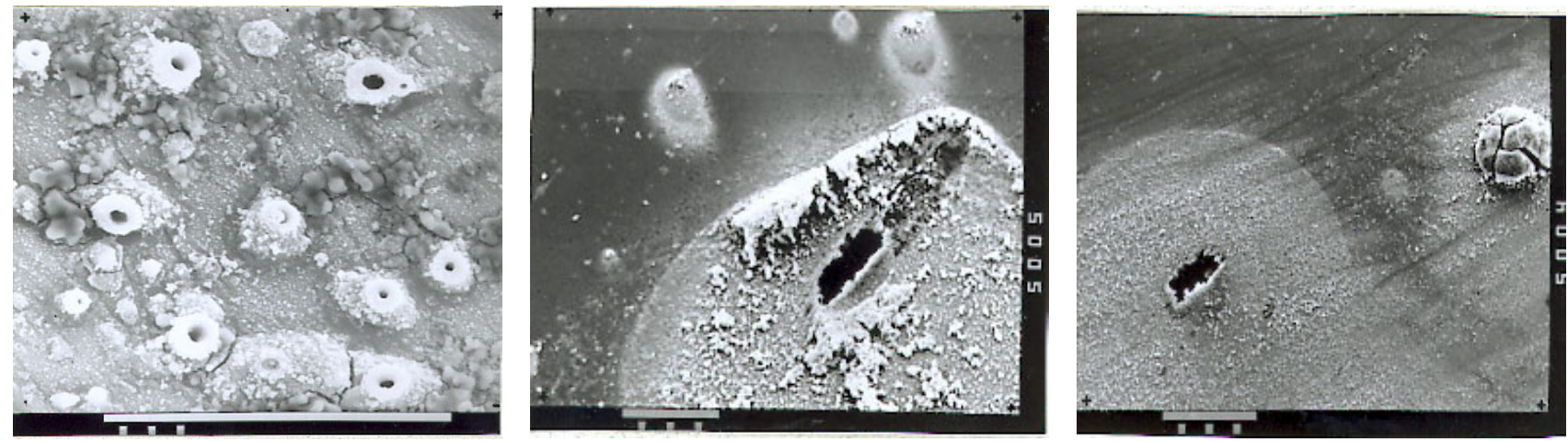

Figure 1. SEM photomicrographs showing various configurations of pits on Al 6061 after anodic polarization in $3 \% \mathrm{NaCl}$ at pitting potential $\left(\mathrm{E}_{\text {cpit. }}\right)$.
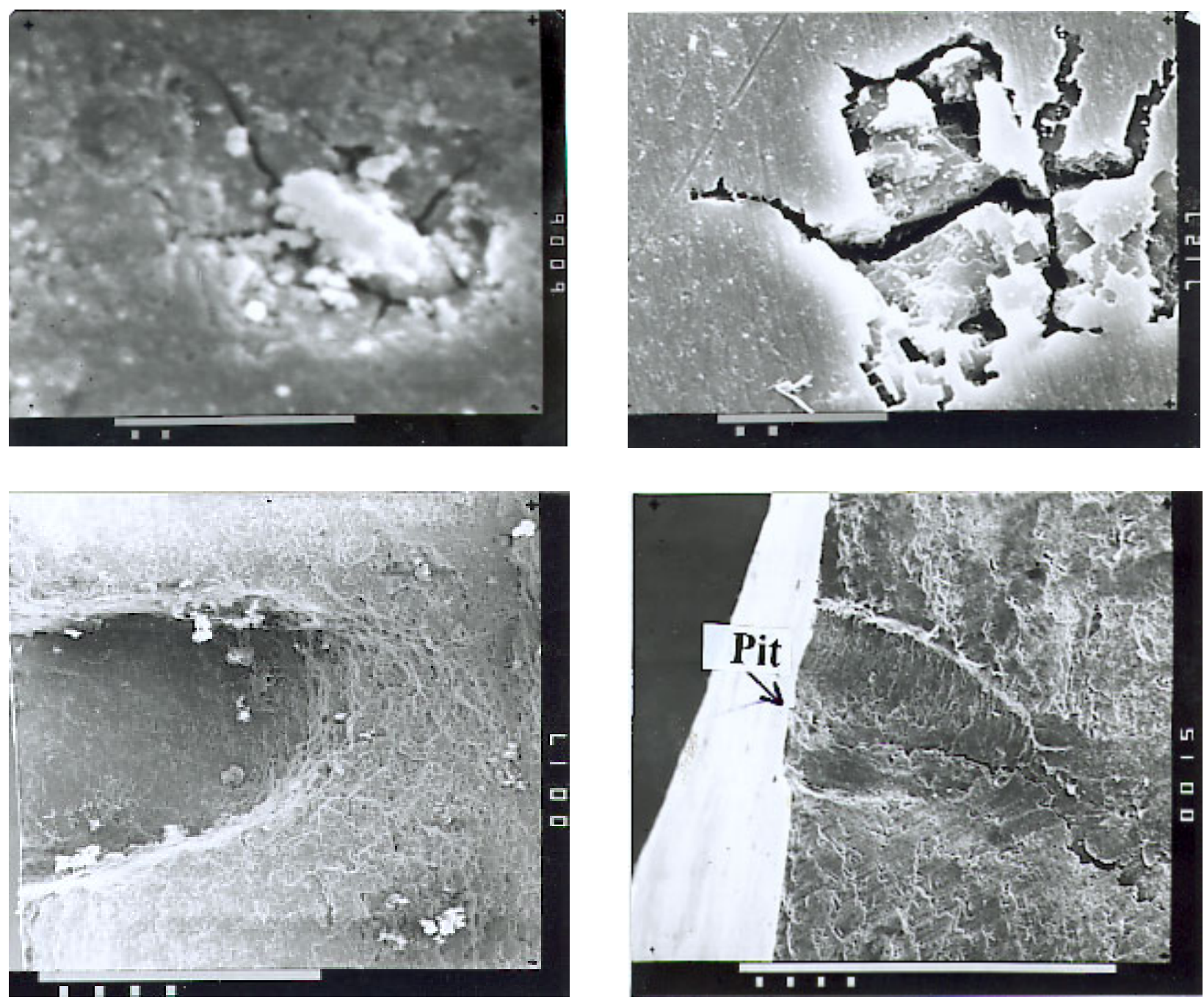

Figure 2. SEM photmicrographs of intergranular cracks and secondary cracks associated with pitting on $\mathrm{Al} 6061$ cycled in $3 \% \mathrm{NaCl}$. 